\title{
Controlled release in hard to access places by poly(methyl methacrylate) microcapsules triggered by gamma irradiation
}

Kostrzewska, Malgorzata; Ma, Baoguang; Javakhishvili, Irakli; Hansen, Jens H.; Hvilsted, Søren; Skov, Anne L.

Published in:

Polymers for Advanced Technologies

Link to article, DOI:

10.1002/pat.3532

Publication date:

2015

Document Version

Peer reviewed version

Link back to DTU Orbit

Citation (APA):

Kostrzewska, M., Ma, B., Javakhishvili, I., Hansen, J. H., Hvilsted, S., \& Skov, A. L. (2015). Controlled release in hard to access places by poly (methyl methacrylate) microcapsules triggered by gamma irradiation. Polymers for Advanced Technologies, 26(9), 1059-1064. https://doi.org/10.1002/pat.3532

\section{General rights}

Copyright and moral rights for the publications made accessible in the public portal are retained by the authors and/or other copyright owners and it is a condition of accessing publications that users recognise and abide by the legal requirements associated with these rights.

- Users may download and print one copy of any publication from the public portal for the purpose of private study or research.

- You may not further distribute the material or use it for any profit-making activity or commercial gain

- You may freely distribute the URL identifying the publication in the public portal 


\title{
Controlled release in hard to access places by PMMA microcapsules triggered by gamma irradiation
}

\author{
Malgorzata Kostrzewska ${ }^{1}$, Baoguang $\mathrm{Ma}^{1}$, Irakli Javakhishvili ${ }^{1}$, Jens H. Hansen ${ }^{2}$, \\ Søren Hvilsted ${ }^{1}$, Anne L. Skov ${ }^{1}$
}

${ }^{1}$ Danish Polymer Centre, Department of Chemical and Biochemical Engineering,
Søltofts Plads Building 227, Technical University of Denmark, 2800 Kgs. Lyngby, Denmark
${ }^{2}$ Mærsk Oil Research and Technology Centre, Education City, P. O. Box 210112, Doha, Qatar

Gamma irradiation was investigated as a triggering stimulus for the activation of poly(methyl methacrylate) (PMMA) microcapsules. PMMA was exposed to varying doses of irradiation and analysed by DSC, SEC and NMR. It was found that the glass transition temperature $\left(T_{g}\right)$ of the polymer decreases at low irradiation doses. Additionally, $T_{g}$ can be physically adjusted by adding a plasticizer and both kinds of microcapsules were successfully prepared, with non-plasticized and plasticized PMMA shell. Finally, impermeable microcapsules after irradiation were shown to become permeable and release an encapsulated PDMS cross-linker, which enables the remotely controlled formation of PDMS silicones in traditionally unavailable places. Therefore, the activation method has significant implications for industrial application.

Keywords: microcapsules, controlled release, gamma irradiation

\section{Introduction}

Microencapsulation attracts attention mainly due to the way in which it controls release [1, 2]. The technique allows for the preparation of innovative materials appearing more frequently in commercial products. For example, medicines programmed to release active substances reduce harmful side effects and frequency of use [3]. Similarly, many cosmetics contain microcapsules in order to achieve prolonged action; for instance, encapsulated volatile fragrances last longer. Other examples of applications and benefits include the masking of unpleasant tastes by the food industry, the controlled release of nutrients in soil for farming, textiles and self-healing materials $[4,5]$.

To obtain the desired release rate from microcapsules, the correct form of activation must be chosen. Activation in this case is a process in which the properties of a microcapsule's shell change in order to deliver enclosed material into the surrounding environment. 
Various sorts of stimuli, such as light, mechanical, thermal or magnetic exposure, can trigger this release. Hence, the choice of the shell material is dictated by the type of triggering stimulus. For instance, a light-triggered release from a capsule is achieved through the usage of photo-responsive or photo-cleavable groups $[6,7]$. By adjusting the concentration of photosensitive material in the shell structure, different release rates are achieved. Moreover, mechanical activation is often employed in self-healing resins [8], where the selfhealing mechanism is triggered through the release and reaction of the healing agent in the region of damage. Another example is thermal activation, which leads to the melting of the shell at higher temperatures, thereby resulting in capsule collapse [9]. Furthermore, the activation of magnetically triggered capsules, the most frequently used in drug delivery systems [10], occurs only in tissues subjected to oscillating magnetic fields, thus allowing for accurate navigation of the drug due to the presence of magnetic nanoparticles.

Poly(methyl methacrylate), PMMA, has been used widely as a shell material for encapsulating liquid compounds [11-13]. PMMA is brittle and hard below the glass transition temperature $\left(T_{g}\right)$, but it becomes soft and flexible at higher temperatures. Heating microcapsules above the $T_{g}$ of PMMA leads to the shell melting and thus acts as a triggering stimulus; for instance, the formation of an elastomer network in reservoir rocks may be delayed through the encapsulation of the PDMS cross-linker. In order to use the microcapsules in the oil industry, where temperatures in reservoir rock often reach $50^{\circ} \mathrm{C}$, the $\mathrm{T}_{\mathrm{g}}$ of the polymer shell should be higher than $50^{\circ} \mathrm{C}$. However, phase change transition should not appear at too high temperatures, in order to ensure fast microcapsule response. As a result, $\mathrm{PMMA}$ with the $\mathrm{T}_{\mathrm{g}}$ of $60^{\circ} \mathrm{C}$ seems to be a reasonable choice for such a system. In addition, exposure to another external stimulus, which decreases the $T_{\mathrm{g}}$ of the shell, makes microcapsules permeable at lower temperatures.

In this study, gamma irradiation was investigated as a triggering stimulus, because it penetrates through many materials and thus allows for the remote activation of microcapsules in inaccessible places. Moreover, gamma irradiation changes the structure of polymers and consequently influences their $T_{g}$. PMMA generally undergoes chain degradation at low irradiation doses, but cross-linking can take place when higher doses are delivered to the material [14]. As a result, the $T_{g}$ may decrease or increase, respectively. 
Furthermore, polymers with purposely low $\mathrm{M}_{\mathrm{w}}$ designed were examined, because the glass transition temperature of short chain polymers is known to depend strongly on their molecular weight [15]. Chemical and physical modifications were also tested with the aim of promoting chain scission, i.e. to increase the response for a given dose.

\section{Experimental section}

\section{Chemicals}

Hydride-functional PDMS cross-linker (HMS-301, $M_{w}=2000 \mathrm{~g} / \mathrm{mol}$, Gelest), vinyl-terminated PDMS (DMS-V35, $M_{w}=49500 \mathrm{~g} / \mathrm{mol}$, Gelest), poly(vinyl alcohol) (PVA, $M_{w}=22000 \mathrm{~g} / \mathrm{mol}$, Fluka), azo-bis-isobutyronitrile (AIBN, Ventron) and the platinum cyclovinylmethyl siloxane complex (Catalyst 511, Hanse Chemie AG) were used as received. Methyl methacrylate (MMA, Aldrich) was passed through an aluminum oxide column to remove any inhibitor. All other chemicals were acquired from Aldrich and used as received.

\section{Preparation of materials}

Non-plasticised PMMA

Two kinds of non-plasticised PMMA were examined. Sample named as PMMA_1 is a commercially available polymer, whereas sample labeled as PMMA_2 was synthesized following the procedure: $5.0 \mathrm{~g}$ methyl methacrylate, $20.0 \mathrm{~g}$ toluene, $0.35 \mathrm{~g}$ AIBN and $0.36 \mathrm{~g}$ thioglycolic acid - a chain transfer agent (CTA) - were charged to a $50 \mathrm{~mL}$ round-bottom flask equipped with a magnetic stirrer and sealed with a rubber septum. The flask was then flushed with nitrogen at room temperature for 15 minutes, and the reaction was run at $60^{\circ} \mathrm{C}$ for $24 \mathrm{~h}$ under a nitrogen atmosphere. The round-bottom flask was then cooled, and the toluene was removed by a rotary evaporator at room temperature. The material left in the flask was then dissolved in dichloromethane (DCM) and precipitated by hexane. Finally, the precipitated PMMA was washed additionally by hexane until all impurities had been removed.

Fluorinated derivatives - 2,2,2-trifluoroethyl methacrylate - with various molecular weights were also synthesized and the preparation details are described in a supplementary information. 


\section{Plasticised PMMA}

Firstly, PMMA_1 was dissolved in DCM and various amounts of DBP were added to the solution. After evaporating DCM at room temperature for two days, the $T_{\mathrm{g}}$ of plasticized samples were evaluated. Sample with required $\mathrm{T}_{\mathrm{g}}$ was chosen for further analysis, and called as PMMA_3.

\section{PMMA microcapsules containing a PDMS cross-linker}

The preparation of microcapsules with PMMA_1 as a shell and a cross-linker core was studied extensively in our research group $[11,16]$. The phase separation technique was employed as briefly described here: an oil phase was prepared by adding the PDMS crosslinker HMS-301 (1.5g) to DCM $(75 \mathrm{~mL})$, preceded by dissolving PMMA (1g) in an organic solvent. Afterwards, approximately $77 \mathrm{~mL}$ of aqueous emulsifier solution (1\% PVA) was charged to a $250 \mathrm{~mL}$ conical flask. The aqueous phase was mechanically stirred at $2000 \mathrm{rpm}$ for 2-5 min (Eurostar Digital Ika Labortechnik), and the oil phase was added drop-wise over 60 seconds to form an oil-in-water emulsion. The agitation was kept for $1 \mathrm{~h}$ at around 750 $\mathrm{rpm}$, before pouring the emulsion into another $120 \mathrm{~mL}$ of the aqueous surfactant solution (1\% PVA). The diluted emulsion was rotary evaporated, in order to remove residual DCM. The dispersion of microcapsules was filtered by use of a filtration pump and qualitative filter paper, 413 (particle retention: 5-13 $\mu \mathrm{m}$ ). Finally, the product was washed with distilled water $(\sim 1.5 \mathrm{~L})$ and dried at room temperature.

Microcapsules with plasticised PMMA shell were prepared analogously via the phase separation technique. Therefore, the oil phase consisted of DCM, PMMA, HMS-301 and DBP.

\section{Gamma irradiation experiments}

Each sample weighed approximately $1 \mathrm{~g}$, and the samples were irradiated at room temperature with various doses of gamma rays, by using a ${ }^{60}$ Cobalt gamma cell at the Center for Nuclear Technologies, Danish Technical University, Ris $\varnothing$ Campus. The dose rate was approximately $1 \mathrm{~Gy} \mathrm{~s}^{-1}$. Nominal doses were given as doses to water, and the maximum dose was $10 \mathrm{kGy}$. 


\section{Analytical methods}

The glass transition temperature of the shell polymers was measured by employing a DSC Q1000 calorimeter (TA Instruments) at heating/cooling rates of $10^{\circ} \mathrm{C} \mathrm{min}^{-1}$. The samples weighed approximately $2-5 \mathrm{mg}$. The glass transition temperatures were calculated by means of the second heating scan as the temperature of the halfway point of the jump in heat capacity when the material changed from a glassy to a rubbery state. To investigate the chemical structure of the polymers, ${ }^{1} \mathrm{H}$ NMR characterisation was performed on a Bruker $250 \mathrm{MHz}$ spectrometer using $\mathrm{CDCl}_{3}$ as a solvent. All spectra were recorded across 32 scans, while size-exclusion chromatography (SEC) was performed on a Viscotek GPCmax VE-2001 instrument equipped with a Viscotek TriSEC Model 302 triple detector using two PLgel mixed-D columns from Polymer Laboratories. Samples were run in THF at room temperature and at a rate of $1 \mathrm{~mL} / \mathrm{min}$. Scanning electron microscopy (SEM) images were recorded on FEI Inspect S on samples that were metallised with gold using a Cressington 208HR Sputter Coater, and the reactivity of the PMMA microcapsules was examined by using a controlled strain rheometer (Ares G2, TA-Instruments). The strain amplitude was $2 \%$ and the frequency was kept at $1 \mathrm{~Hz}$, which has previously been shown as a suitable frequency for tracking additional curing silicone [16]. Microcapsules were mixed with DMSV35 (vinyl-terminated PDMS) at a mass ratio of $1: 10$, and the dynamic modulus $\left(G^{\prime}\right)$ was measured at different temperatures.

\section{Results and discussion}

The addition of plasticiser was explored as an easy and fast method to adjust $T_{\mathrm{g}}$ [17]. Figure 1 shows the $T_{\mathrm{g}}$ of plasticised PMMA_1 with different amounts of DBP.

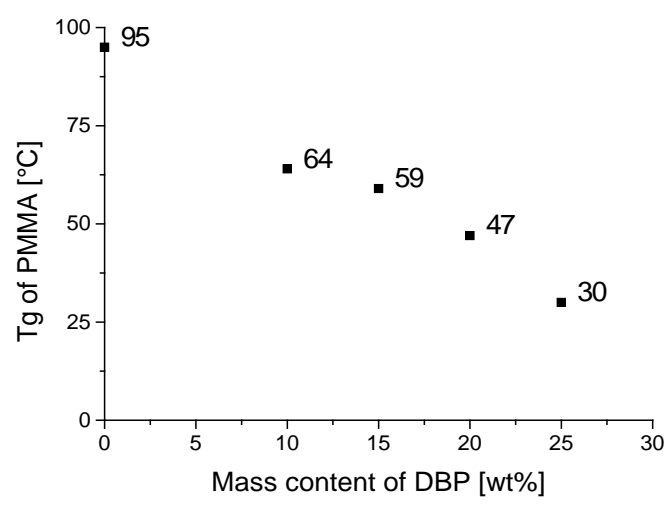

Figure 1. $T_{g}$ of PMMA_1 containing various plasticizer concentrations. 
As expected, plasticised PMMA with DBP possess decreasing $T_{g}$ with increasing amount of plasticiser. Since the sample with $15 \%$ of DBP showed a $T_{g}$ closest to the desired activation temperature $\left(60^{\circ} \mathrm{C}\right)$, it was irradiated and used in the preparation of the microcapsules and since now called as PMMA_3.

Prepared samples were exposed to different irradiation doses and table 1 shows the $T_{\mathrm{g}}$ and molecular weights of the studied polymers.

Table 1. Glass transition temperatures and molecular weights of non-irradiated and irradiated polymers.

\begin{tabular}{|c|c|c|c|c|c|c|}
\hline \multirow{2}{*}{$\begin{array}{c}\text { Absorbed } \\
\text { dose } \\
\text { [kGy] }\end{array}$} & \multicolumn{2}{|c|}{ PMMA_1 } & \multicolumn{2}{|c|}{ PMMA_2 } & \multicolumn{2}{|c|}{ PMMA_3 } \\
\hline & $\mathrm{T}_{\mathrm{g}}\left[{ }^{\circ} \mathrm{C}\right]$ & $\mathrm{M}_{\mathrm{w}}[\mathrm{g} / \mathrm{mol}]$ & $\mathrm{T}_{\mathrm{g}}\left[{ }^{\circ} \mathrm{C}\right]$ & $\mathrm{M}_{\mathrm{w}}[\mathrm{g} / \mathrm{mol}]$ & $\mathrm{T}_{\mathrm{g}}\left[{ }^{\circ} \mathrm{C}\right]$ & $\mathrm{M}_{\mathrm{w}}[\mathrm{g} / \mathrm{mol}]$ \\
\hline 0 & 95 & $\begin{array}{l}15000 \\
\text { PDI } 2.3\end{array}$ & 58 & $\begin{array}{l}200 *^{*} \\
\text { PDI } 1.6\end{array}$ & 59 & $\begin{array}{l}15000^{*} \\
\text { PDI } 2.5\end{array}$ \\
\hline 0.3 & 92 & 14500 & 53 & & - & \\
\hline 0.5 & 90 & 15000 & 54 & & - & \\
\hline 0.8 & 86 & 14000 & 47 & & 60 & \\
\hline 1.6 & 83 & 13500 & 46 & & 52 & \\
\hline 10 & 89 & 13500 & 53 & & 57 & \\
\hline
\end{tabular}

*SEC calibration was done for standard PMMA molecular weights. Therefore, SEC results are presented only for PMMA_1, since sample PMMA_2 has a very low molecular weight and plasticised sample is a mixture of two components.

The polymers had lower glass transition temperatures after irradiation, due to induced chain scission. Scission is a two-stage process initiated at unsaturated chain ends, and it is followed by random scissions of the backbone [18]. Therefore, in the first stage molecular weight does not change significantly since the cleavage of the pendant and the end groups takes place. Scission of the main backbone causes observable changes in chain length. Since the molecular weights of irradiated samples did not change significantly, it is assumed that end-chain degradation mainly took place. Additionally, Figure 2 presents ${ }^{1} \mathrm{H}$ NMR spectra of sample PMMA_1 before and after irradiation. The PMMA gives four main resonances in the ${ }^{1} \mathrm{H}$ NMR spectrum. Signals at 0.7 and $1 \mathrm{ppm}$ correspond to the protons of the methyl groups attached to the carbon of the backbone of the PMMA. The peak at $1.7 \mathrm{ppm}$ is attributed to the protons of the methylene groups from the backbone, and the peak at $\sim 3.5 \mathrm{ppm}$ refers to the protons of the methyl groups attached to the ester groups of the side chains of the 
PMMA. Peaks attributed to a double bond of methyl methacrylate (MMA) are also observed in the spectrum at 5.5 and $6.0 \mathrm{ppm}$ even at dose $0 \mathrm{kGy}$. Integration of the signals indicated that amount of the monomer in the sample decreased during the irradiation due to volatility of MMA. It means that presence of the residue monomer did not influence on the $\mathrm{T}_{\mathrm{g}}$ loss as it could be assumed since monomers are main degradation products of PMMA [18]. Data show that the structure of PMMA did not change significantly, what confirmed our assumptions that a slight change in chain length was sufficient to influence polymer properties.

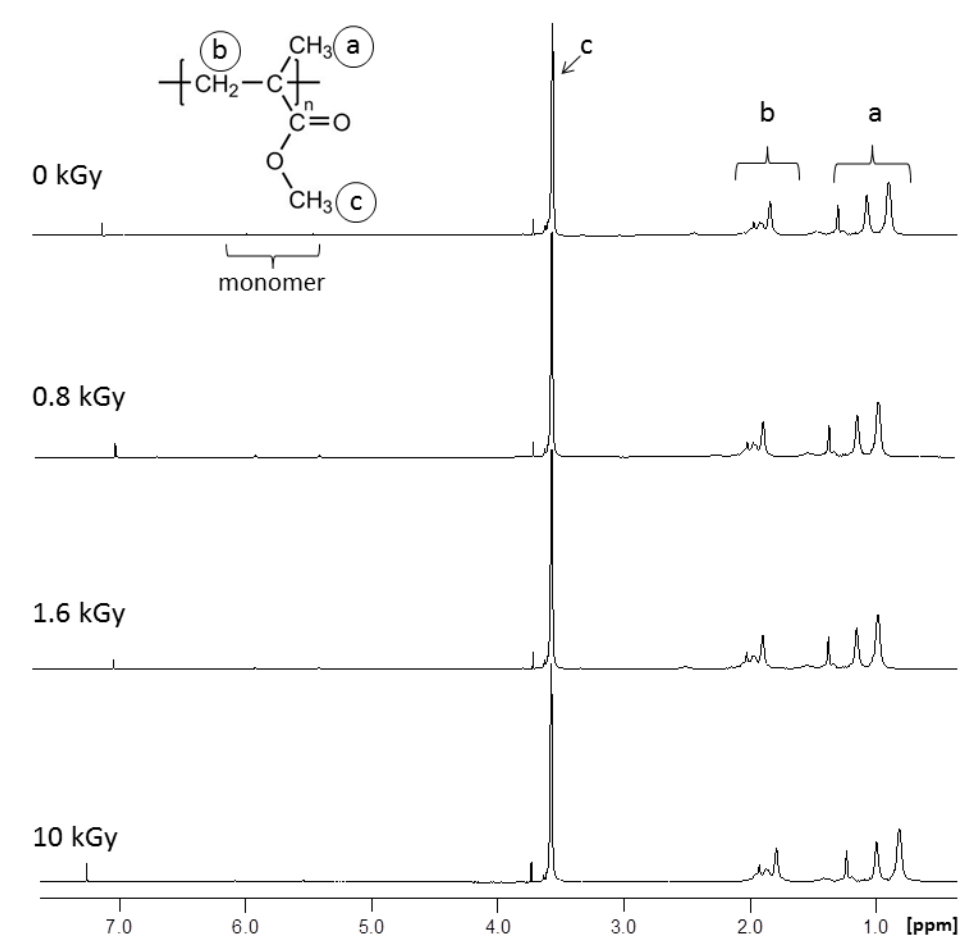

Figure 2. ${ }^{1} \mathrm{H}$ NMR spectra of PMMA_1.

At the highest irradiation doses $\mathrm{T}_{\mathrm{g}}$ started to increase slightly, due to a cross-linking reaction [19]. When the concentration of degradation products increases, the possibility that macroradicals will recombine with each other also increases. Since PMMA monomers are very susceptible to free radical polymerisation, products formed during the degradation process cross-link with each other. Therefore, the glass transition temperature of the PMMA increased.

Irradiated sample PMMA_3 behaved similarly to the non-plasticised sample. In both cases, the lowest $\mathrm{T}_{\mathrm{g}}$ was observed at $1.6 \mathrm{kGy}$ and started to increase at higher doses. Nevertheless, 
the influence of irradiation was less noticeable for the plasticised samples, as plasticisers protect polymer compositions against chain scission. For instance, aromatic groups have the ability to effectively degrade absorbed energy and increase the radiation stability of a mixture $[20,21]$. Furthermore, plasticisers act as lubricants between adjacent polymer chains and allow for greater molecular movement. This increased mobility of chains leads to a higher rate of migration of free radicals, which in turn increases the possibility of radical collision. Therefore, the impact of irradiation on $T_{g}$ was less noticeable for the plasticised sample, though PMMA degradation did take place.

Fluorinated derivatives were also exposed to gamma irradiation, but no clear relationship between the irradiation dose and $T_{g}$ was observed. All experimental details are presented in supplementary information.

\section{PMMA microcapsules containing a PDMS cross-linker}

Microcapsules with a non-plasticised PMMA_1 and a plasticised PMMA_3 shell containing a high viscosity PDMS cross-linker agent were prepared using the phase separation technique. Figure 3 presents SEM photos of the capsules. The diameter of the microcapsules falls between 3-40 $\mu \mathrm{m}$, with the average size at around $20 \mu \mathrm{m}$, while the mass content of the encapsulated cross-linker, determined by the ${ }^{1} \mathrm{H}$ NMR method, was approximately $50 \%$ [11].
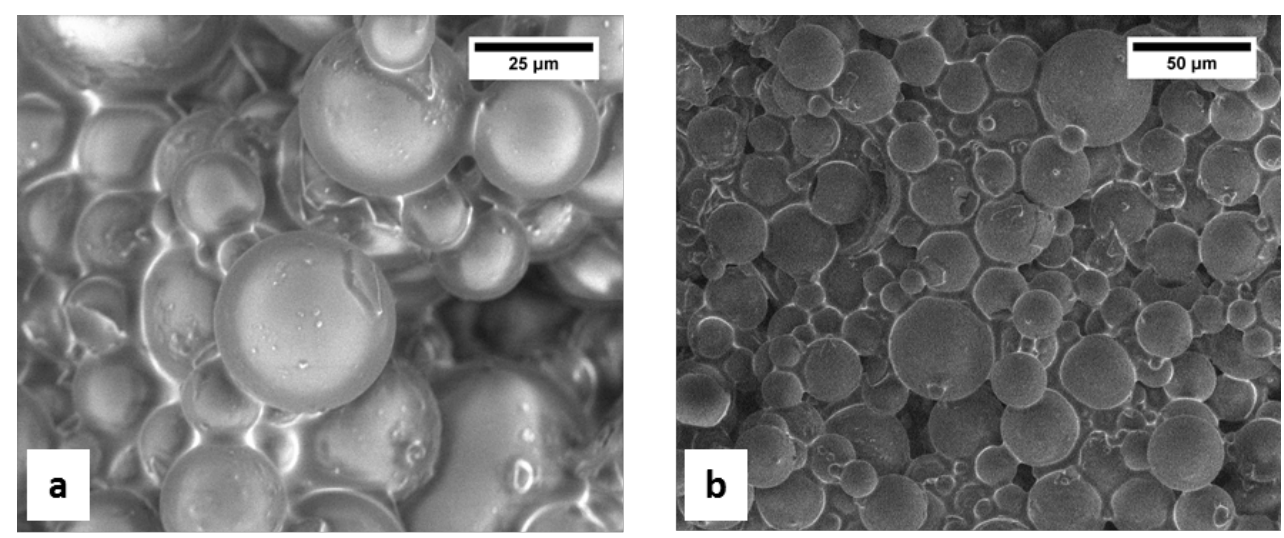

Figure 3. SEM photos of microcapsules with a) a non-plasticised and b) a plasticised PMMA_1 shell. 
The presence of DBP in the microcapsule shells was verified by ${ }^{1} \mathrm{H}$ NMR analysis, and the spectra of the microcapsules are shown in Figure 4. The ${ }^{1} \mathrm{H}$ NMR spectrum of the plasticised microcapsules should show resonances attributed to the PMMA, cross-linker and DBP. Peaks attributed to hydrogens in a PMMA structure were previously described. A spectrum of the cross-linker shows peak at $4.7 \mathrm{ppm}$, which is assigned to the hydrogens attached to the silicon atom, and the peak at $0 \mathrm{ppm}$ corresponds to the protons of the methyl groups linked to the silicone atom. A spectrum of DBP shows six peaks. Resonances at 7.7 and 7.5 $\mathrm{ppm}$ are ascribed to protons in the DBP aromatic group. At $4.3 \mathrm{ppm}$ there is a signal arising from the metoxy protons of the butoxy group. Two peaks at 1.7 and $1.4 \mathrm{ppm}$ come from protons in $-\mathrm{CH}_{2}$ - groups and a resonance at $1 \mathrm{ppm}$ is ascribed to the protons from the methyl group. As a spectrum of microcapsules with plasticized shell shows all these peaks, it proves that DBP was incorporated into the shell. The chemical structure of the microcapsule was also inferred from the FTIR studies [11]. No evidence of hydroxyl groups (OH) in the region of $3300 \mathrm{~cm}^{-1}$ from the emulsifier (PVA) was detected via IR spectroscopy meaning that all PVA was washed out during purification step.

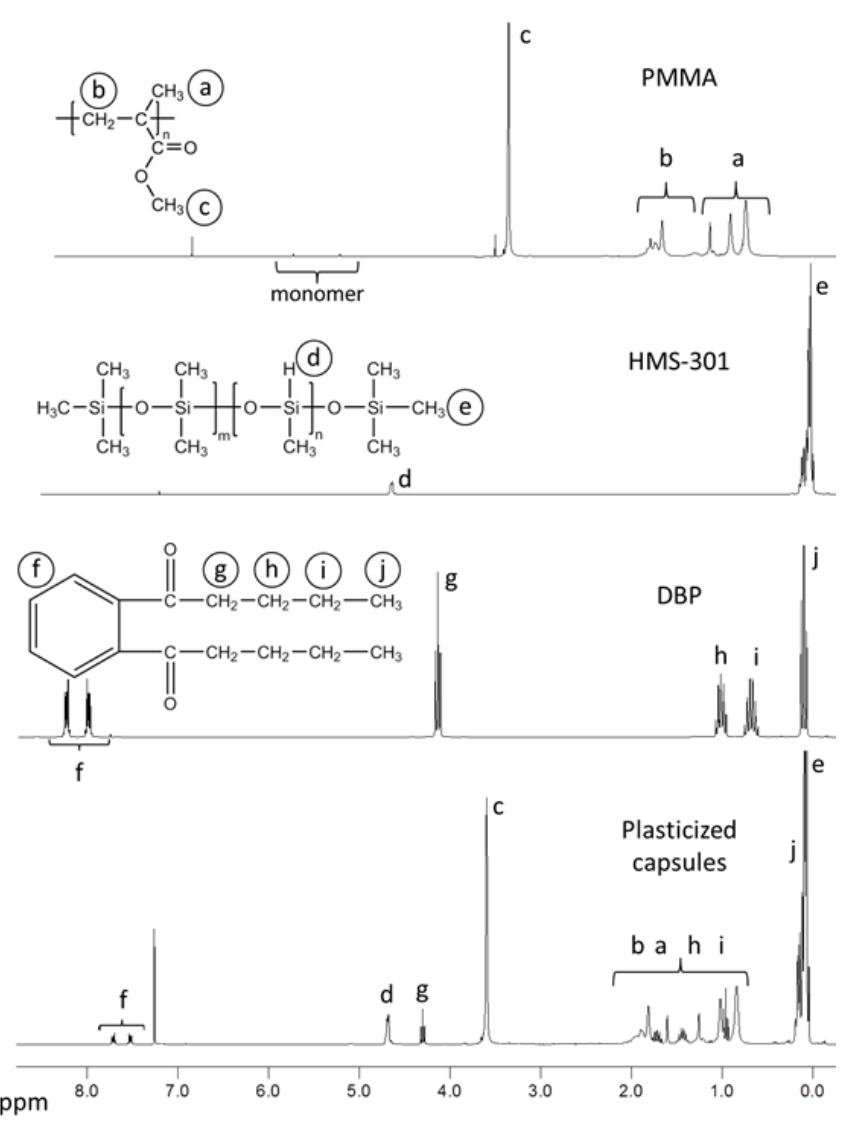

Figure $4 .{ }^{1} \mathrm{H} N M R$ spectra of microcapsules plasticised shells and the components. 
Adding plasticiser did not influence the preparation process of the microcapsules. Since DBP is soluble in DCM and miscible with PMMA, plasticised PMMA microcapsules were successfully prepared.

\section{Activation of the microcapsules}

Microcapsules with a PMMA_1 shell were exposed to a $1.6 \mathrm{kGy}$ dose, and their reactivity with vinyl-terminated DMS-V35 was examined by using a controlled strain rheometer. The dynamic moduli of the mixture were measured at different temperatures, the results for which are presented in Figure 5. Non-irradiated microcapsules reacted with DMS-V35 at $100^{\circ} \mathrm{C}$, and a significant increase in storage modulus was observed. PMMA passes through phase change transition at $95^{\circ} \mathrm{C}$ and microcapsules become permeable. Below $100^{\circ} \mathrm{C}$, the microcapsules were relatively stable, since only minor changes in $G^{\prime}$ were observed - the remaining cross-linker on the surface of the shell could be a reason for this result. Although the storage modulus increased below $T_{g}$ of the PMMA, it is evident that the cross-linking reaction took place mainly at $100^{\circ} \mathrm{C}$. On the other hand, a dramatic increase in $\mathrm{G}^{\prime}$ was observed at $30^{\circ} \mathrm{C}$ for irradiated microcapsules despite the fact that the PMMA $T_{\mathrm{g}}$ was around $80^{\circ} \mathrm{C}$, which means that not only does the $\mathrm{T}_{\mathrm{g}}$ of polymer change during irradiation, but local heating effects can affect the local structure of the PMMA shell.

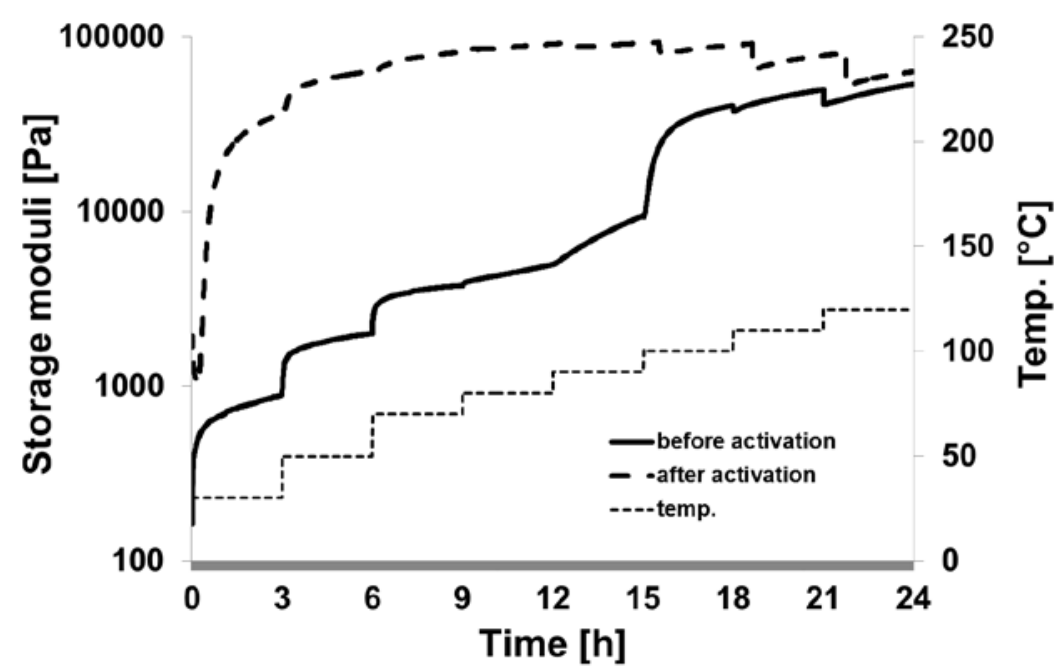

Figure 5. The reactivity of PMMA_1 microcapsules with DMS-V35, before and after irradiation. The mass ratio between the compounds was 1:10, respectively. 


\section{Conclusions}

This paper presents a comprehensive study of the potential application of gamma irradiation as a triggering stimulus for PMMA microcapsule remote activation. It was found that PMMA undergoes chain degradation at small doses of gamma irradiation, and therefore the glass transition temperature is decreased. The effect of chain degradation is more noticeable for PMMA with relatively low molecular weight. Moreover, physical modification of the microcapsules' shell by adding plasticiser, allows for the easy and fast control of the initial $\mathrm{T}_{\mathrm{g}}$ of the microcapsule shell.

Secondly, the reactivity of microcapsules with vinyl-terminated PDMS shows that a crosslinking reaction takes place with high efficiency after $y$-irradiation activation. Before activation, microcapsules are stable at a wide range of temperatures, but when they are exposed to gamma irradiation, an encapsulated cross-linker releases at lower temperatures and an elastomer network is created. Therefore, two main advantages of the usage of the $\gamma$ irradiation stimulus are the possibility of remotely activating microcapsules in unreachable places and a significant decrease in activation temperature.

\section{Acknowledgments}

The authors would like to thank Arne Miller and Jim Thorslund Andersen from the Center for Nuclear Technologies at DTU for helping with the radiation experiments. This project was financially supported by Mærsk Oil \& Gas Research, Qatar.

\section{References}

1. A. Abbaspourrad, S. S. Datta, D. A. Weitz, Langmuir, 2013, 29, 12697-12702

2. S. Zhang, Y. Zhou, W. Nie, L. Song, J. Li, B. Yang, J. Mater. Chem. 2013, 1, 4331-4337

3. S. H. Hu, C.H. Tsai, C. F. Liao, D.M. Liu, S. Y. Chen, Langmuir, 2008, 24, 11811-11818

4. A. P. Esser-Khan, S. A. Odom, N. R. Sottos, S. R. White, J. S. Moore, Macromolecules, 2011, 44, 5539-5553

5. Y. Taguchia, N. Saitoa, K. Fuchigamib, M. Tanakaa, Polymer. Adv. Tech., .2014, 25, $41-47$

6. T. Dispinar, C. A L. Colard, F. E. Du Prez, Polym. Chem., 2013, 4, 763-772 
7. E. M. Rosenbauer, M. Wagner, A. Musyanovych, K. Landfester, Macromolecules, 2010, 43, 5083-5093

8. Zhao. Yang, Z. Wei, L. Le-ping, W. Si-jie, L. Wu-jun, Appl. Surf. Sci., 2012, 258, 19151918

9. J. Abedi-Koupai, J. Varshosaz, M. Mesforoosh, A. Hossein Khoshgoftarmanesh, J. Plant Nutr., 2012, 35, 1130-1138

10. D. Qiu, X. An, Colloids Surf. B, 2013, 104, 326-329

11. L. Gonzalez, M. Kostrzewska, M. Baoguang, L. Li, J. H. Hansen, S. Hvilsted, A. L. Skov, Macromol. Mater. Eng. 2014, 299, 1259-1267

12. A. Loxley, B. Vincent, J. Colloid Interface Sci, 1998, 208, 49-62

13. M. Li, O. Rouaud, D. Poncelet, Int. J. Pharm., 2008, 363, 26-39

14. I. Y. Al-Qaradawi, D. A. Abdulmalik, N. K. Madi, M. Almaadeed, Phys. Stat. Sol., 2007, $4,3727-3730$

15. X. Lu, B. Jiang, Polymer, 1991 32, 471-478

16. B. Ma, J. H. Hansen, S. Hvilsted, A. Skov, RSC Adv., 2014, 4, 47505-47512

17. G. M. Vinhas, R. M. Souto-Maior, C. M. Lapa, Y. Medeiros Bastos de Almeida, Materials Research, 2003, 6, 497-500

18. M. A. Rauf, I. C. McNeillt, Polym. Degrad. Stabil., 1993, 40, 263-266

19. E.H. Lee, G.R. Rao, L.K. Mansur, Radiat. Phys. Chem., 1999, 55, 293-305

20. E. Choi, D. J. T. Hill, K. Y. Kim, J.H. O’Donnell, P. J. Pomery, Polymer. Adv. Tech., 1998, 9, 52-61

21. E. R. Booser, W. W. Gardner, CRC Handbook of Lubrication (Theory and Practice of Tribology), Volume I-Application and Maintenance, Taylor \& Francis Group, Boca Raton, 2006 